\title{
ESTIMATIVA DA ERODIBILIDADE EM ENTRESSULCOS DE LATOSSOLOS DO RIO GRANDE DO SUL ${ }^{(1)}$
}

\author{
Maria Cândida Moitinho Nunes ${ }^{(2)}$ \& Elemar Antonino Cassol ${ }^{(3)}$
}

\begin{abstract}
RESUMO
Os modelos de predição e estimativa da erosão hídrica do solo geralmente necessitam de grande quantidade de propriedades, a maioria obtida com o uso de chuva simulada em campo e, ou, laboratório. $O$ uso de propriedades de obtenção mais rápida, simples e de baixo custo, como textura, teor e tipo de óxidos e estabilidade dos agregados em água, pode contribuir para facilitar a estimativa do fator de erodibilidade do solo em entressulcos $\left(K_{i}\right)$. Este estudo teve como objetivos: i) determinar o fator de erodibilidade em entressulcos (Ki) de alguns Latossolos do Rio Grande do Sul; ii) avaliar o uso do percentual de areia e de argila, conforme proposto pelo modelo WEPP, para a estimativa do fator $K_{i}$ e iii) identificar quais as propriedades que melhor se correlacionam com o fator $\mathbf{K}_{\mathrm{i}}$. Foram estudados três Latossolos de diferentes classes texturais: 1) Latossolo Vermelho aluminoférrico (LVaf) com 721,9 $\mathrm{g} \mathrm{kg}^{-1}$ de argila; 2) Latossolo Vermelho distroférrico (LVdf) com 629,4 g $\mathrm{kg}^{-1}$ de argila; 3) Latossolo Vermelho distrófico (LVd) com $215,1 \mathrm{~g} \mathrm{~kg}^{-1}$ de argila. A erosão em entressulcos foi determinada em laboratório, em solo mobilizado e descoberto, sob pré-umedecimento e chuva simulada com intensidade média de 88 $\mathrm{mm} \mathrm{h}^{-1}$. Utilizou-se parcela experimental com área útil de $0,36 \mathrm{~m}^{2}$ e declividade de 0,09 $\mathrm{m} \mathrm{m}^{-1}$. Os solos com maior teores de argila e de óxidos de Fe e com maior estabilidade de agregados em água apresentaram menor susceptibilidade à erosão em entressulcos. $\mathrm{O}$ fator de erodibilidade do solo em entressulcos (Ki) foi de $\mathbf{0 , 7 6} \times 10^{6}$ $\mathrm{kg} \mathrm{s} \mathrm{m}^{-4}$, para o LVaf (Erechim); 0,97 x $10^{6} \mathrm{~kg} \mathrm{~s} \mathrm{~m}^{-4}$, para o LVdf (Santo Ângelo), e 1,48 $\times 10^{6} \mathrm{~kg} \mathrm{~s} \mathrm{~m}^{-4}$, para o LVd (Cruz Alta). $O$ índice de estabilidade de agregados em água teve correlação altamente significativa $\left(\mathrm{r}=-\mathbf{0 , 9 0 * * * )}\right.$ com o fator $\mathrm{K}_{\mathrm{i}}$. $\mathrm{O}$ uso dos teores de areia e de argila, conforme sugerido pelo modelo WEPP, não foi adequado para estimar o fator $\mathrm{K}_{\mathrm{i}}$. Os teores de argila e de óxido de Fe, extraído com oxalato amônio ácido $\left(\mathrm{Fe}_{\mathrm{o}}\right)$, explicaram $97 \%(\mathrm{p}<0,01)$ da variação no fator $\mathrm{K}_{\mathrm{i}}$ dos Latossolos estudados.

Termos de indexação: predição da erosão hídrica, parâmetros do solo, estabilidade de agregados.
\end{abstract}

\footnotetext{
(1) Parte da Tese de Doutorado do primeiro autor, apresentada ao Programa de Pós-Graduação em Ciência do Solo, Faculdade de Agronomia, Universidade Federal do Rio Grande do Sul - UFRGS. Porto Alegre, RS. Trabalho apresentado no XXXI Congresso Brasileiro de Ciência do Solo, 2007 (Gramado, RS).

(2) Professora Adjunta da Faculdade de Agronomia - Cáceres, Universidade do Estado de Mato Grosso - UNEMAT. CEP: 78200 000. Cáceres, MT. E-mail: nunes.candida@gmail.com.br

(3) Professor Associado do Departamento de Solos da Faculdade de Agronomia. UFRGS. E-mail: cassolea@orion.ufrgs.br
} 


\title{
SUMMARY: PREDICTION OF INTERRILL SOIL ERODIBILITY OF OXISOLS IN RIO GRANDE DO SUL, BRAZIL
}

\begin{abstract}
Models of soil water erosion prediction and estimation are generally based on a series of parameters, normally determined by applying simulated rainfall in the field or laboratory. The use of simpler, faster and cheaper parameters such as texture, content and oxide type and aggregate water stability may contribute to facilitate the estimation of the factor interrill soil erodibility $\left(K_{i}\right)$. The purpose of this study was: i) to determine the interrill soil erodibility of three Brazilian Oxisols; ii) evaluate the use of soil sand and clay contents in the prediction of interrill soil erodibility, as in the WEPP model; iii) verify the correlation among some soil properties and the interrill soil erodibility factor. The interrill soil erosion rates were determined in laboratory, using three Oxisols with different clay content of the State of Rio Grande do Sul, Brazil, under a mean intensity of simulated rainfall of $88 \mathrm{~mm} \mathrm{~h}^{-1}$, applied during $180 \mathrm{~min}$ on bare soil, using experimental interrill plots of $0.36 \mathrm{~m}^{2}$ at a slope of $0.09 \mathrm{~m} \mathrm{~m}^{-1}$ and an initial water tension of $6 \mathrm{kPa}$. The susceptibility of soils with high clay and Fe oxide contents and higher water aggregate stability to interrill erosion was lower. The experimentally determined values of interrill soil erodibility ( $K_{i}$ factor) varied from $0.76 \times 10^{6} \mathrm{~kg} \mathrm{~s} \mathrm{~m}^{-4}$ to $1.48 \times 10^{6} \mathrm{~kg} \mathrm{~s} \mathrm{~m}^{-4}$ for the studied Oxisols. The aggregate water stability index was highly correlated with the interrill soil erodibility factor $\left(r=-0.90^{* * *}\right)$. The use of soil sand and clay contents, as suggested by the WEPP model, did not prove adequate to estimate the interrill soil erodibility (Ki factor). The variation in clay and Fe oxide contents explained $97 \%(p<0.01)$ of the interrill soil erodibility variation.
\end{abstract}

Index terms: : water erosion prediction, soil parameters, aggregate stability.

\section{INTRODUÇÃO}

A erosão hídrica pode levar os solos agrícolas a perderem sua capacidade produtiva, com conseqüente aumento de custos com saúde e alimentação, além da poluição e assoreamento dos cursos d'água. A erosão em entressulcos é causada, principalmente, pela desagregação das partículas do solo, decorrente do impacto da gota da chuva e transporte pelo escoamento superficial laminar. A erosão em sulcos é devida à desagregação, transporte e deposição das partículas do solo pelo fluxo concentrado (Alberts et al., 1995).

A taxa de desagregação do solo em entressulcos é proporcional ao quadrado da intensidade da chuva (Di $\alpha \mathrm{I}^{2}$ ), com a constante de proporcionalidade sendo o parâmetro de erodibilidade do solo em entressulcos $\left(\mathrm{K}_{\mathrm{i}}\right)($ Meyer, 1981; Elliot et al., 1989; Liebenow et al., 1990). No modelo WEPP (Water Erosion Prediction Project) (Flanagan \& Nearing, 1995), o aporte de sedimentos das áreas em entressulcos para os sulcos $\left(D_{1}\right)$ considera a taxa de desagregação $\left(D_{i}\right)$, a intensidade da chuva (I), a taxa de descarga unitária do fluxo $\left(\mathrm{q}_{\mathrm{i}}\right)$ e a declividade $\left(\mathrm{S}_{\mathrm{f}}\right)$. Quando sem efeito de cobertura, de raízes, de selo e crosta e de gelo e degelo, a taxa de aporte de sedimentos dos entressulcos para os sulcos é modelada da seguinte forma (Flanagan et al., 1995):

$$
\mathrm{D}_{\mathrm{l}}=\mathrm{K}_{\mathrm{i}} \mathrm{I} \mathrm{q}_{\mathrm{i}} \mathrm{S}_{\mathrm{f}}
$$

em que $\mathrm{D}_{1}$ é a taxa de aporte de sedimentos provenientes da desagregação em entressulcos $\left(\mathrm{kg} \mathrm{m}^{-2} \mathrm{~s}^{-1}\right)$;
$\mathrm{K}_{\mathrm{i}}$ é o fator de erodibilidade do solo em entressulcos $\left(\mathrm{kg} \mathrm{s} \mathrm{m}^{-4}\right)$; I é a intensidade da chuva $\left(\mathrm{m} \mathrm{s}^{-1}\right)$; $\mathrm{q}_{\mathrm{i}}$ é a taxa de excesso de precipitação pluvial ou descarga unitária do escoamento $\left(\mathrm{m} \mathrm{s}^{-1}\right)$ e $\mathrm{S}_{\mathrm{f}}$ é o fator declividade do solo (adimensional).

O modelo WEPP foi desenvolvido com base em solos sujeitos a uma taxa de intemperismo menor do que a dos Latossolos brasileiros. Nesse modelo, a estimativa do fator de erodibilidade do solo em entressulcos pode ser realizada com os teores de areia e argila (Alberts et al., 1995).

Uma propriedade importante dos solos é o tipo e o teor de óxidos, geralmente abundantes nos Latossolos (Kämpf \& Curi, 2003), os quais apresentam alto grau de intemperismo (Azevedo \& Bonumá, 2004). Alguns Latossolos mostram alta estabilidade de agregados, graças, principalmente, à grande quantidade de óxidos de $\mathrm{Fe} \mathrm{e} \mathrm{Al}$ nesses solos (Azevedo \& Bonumá, 2004). Solos com elevada estabilidade de agregados tendem a ter menor erodibilidade em entressulcos (Meyer \& Harmon, 1984; Albuquerque et al., 2000).

Este estudo teve como objetivos: i) determinar o fator de erodibilidade em entressulcos (Ki) em três Latossolos do Rio Grande do Sul; ii) avaliar o percentual de areia e de argila, conforme proposto pelo modelo WEPP, para a estimativa do fator $\mathrm{K}_{\mathrm{i}}$ e iii) identificar quais as propriedades que melhor se correlacionam com o fator $\mathrm{K}_{\mathrm{i}}$ em alguns Latossolos do Rio Grande do Sul. 


\section{MATERIAL E MÉTODOS}

Este estudo foi desenvolvido nos Laboratórios de Erosão, Física e Química do Solo do Departamento de Solos da Faculdade de Agronomia da Universidade Federal do Rio Grande do Sul. Foram utilizados três Latossolos do Estado do Rio Grande do Sul: i) Latossolo Vermelho aluminoférrico típico textura muito argilosa - LVaf (Embrapa, 2006), da unidade de mapeamento (UM) Erechim (Brasil, 1973); ii) Latossolo Vermelho distroférrico típico textura muito argilosa - LVdf (Embrapa, 2006) da UM Santo Ângelo (Brasil, 1973) e iii) Latossolo Vermelho distrófico típico textura franco-argilo-arenosa - LVd (Embrapa, 2006) da UM Cruz Alta (Brasil, 1973). As amostras foram coletadas em duas condições de uso: natural (solo virgem) e sob cultivo agrícola continuado. $\mathrm{O}$ solo LVaf foi coletado no município de Erechim-RS, em área de mata nativa e sob semeadura direta. O solo LVdf foi coletado no município de Santo Ângelo-RS, e o solo LVd foi coletado no município de Cruz Alta-RS, ambos em áreas de campo natural e sob semeadura direta. Os solos foram coletados na camada de $0-20 \mathrm{~cm}$ e acondicionados em recipientes plásticos (bombonas).

Os solos foram fisicamente caracterizados (Quadros 1 e 2) pela distribuição de diâmetro das partículas do solo (método da pipeta - Embrapa, 1997), densidade de partículas (Blake \& Hartge, 1986), água retida a - $6 \mathrm{kPa}$ (determinado em funil de placa porosa) e estabilidade dos agregados do solo em água (Kemper \& Rosenau, 1986).

Para a caracterização química (Quadro 3), foi determinada a acidez ativa (Mekaru \& Uehara, 1972), o teor de C orgânico (Shimadzu, 2001) e o teor de óxidos de $\mathrm{Fe}$, pela extração com oxalato de amônio ácido $\left(\mathrm{Fe}_{\mathrm{o}}\right)$ (Schwertmann, 1964) e com ditionito-citratobicarbonato/DCB $\left(\mathrm{Fe}_{\mathrm{d}}\right)$ (Mehra \& Jackson, 1960).

A erosão hídrica dos solos em entressulcos foi determinada em laboratório, sob chuva simulada, em solo descoberto, simulando as condições de solo e de superfície proporcionadas pelo preparo convencional. As amostras de solo foram passadas em peneira com abertura de malha de $10 \mathrm{~mm}$ e secas ao ar e à sombra. Foram utilizadas parcelas experimentais de formato quadrado com $0,6 \mathrm{~m}$ de lado e $0,1 \mathrm{~m}$ de profundidade, com bordadura de 0,2 $\mathrm{m}$, mantidas em declividade de $0,09 \mathrm{~m} \mathrm{~m}^{-1}$. O volume das parcelas foi preenchido por duas camadas de solo, sendo a inferior com $3 \mathrm{~cm}$ de espessura de solo e densidade de $1,5 \mathrm{Mg} \mathrm{m}^{-3}$. Sobre essa, foi colocada uma camada de $7 \mathrm{~cm}$ de solo seco ao ar, acondicionada com uma densidade de $1 \mathrm{Mg} \mathrm{m}^{-3}$.

Quadro 2. Índice de estabilidade de agregados em água - IEA (Kemper \& Rosenau, 1986)

\begin{tabular}{lccc}
\hline \multicolumn{1}{c}{ Uso } & $\begin{array}{c}\text { LVaf } \\
\text { (Erechim) }\end{array}$ & $\begin{array}{c}\text { LVdf } \\
\text { (Santo Ângelo) }\end{array}$ & $\begin{array}{c}\text { LVd } \\
\text { (Cruz Alta) }\end{array}$ \\
\hline Natural & $0,97 \mathrm{Aa}$ & $0,98 \mathrm{Aa}$ & $0,38 \mathrm{Ab}$ \\
Cultivado & $0,85 \mathrm{Ab}$ & $0,91 \mathrm{Aa}$ & $0,33 \mathrm{Ac}$ \\
Média & 0,91 & 0,95 & 0,36 \\
\hline
\end{tabular}

LVaf = Latossolo Vermelho aluminoférrico; LVdf = Latossolo Vermelho distroférrico; LVd = Latossolo Vermelho distrófico; Letras maiúsculas comparam médias de linhas na mesma coluna. Letras minúsculas comparam médias de colunas na mesma linha. Médias seguidas pela mesma letra não diferem pelo teste de Tukey a $5 \%$.

Quadro 1. Distribuição de diâmetro das partículas do solo, densidade de partículas (Dp), grau de floculação da argila (GF) e conteúdo volumétrico de água na tensão de $6 \mathrm{kPa}$

\begin{tabular}{|c|c|c|c|c|c|c|c|c|c|c|}
\hline \multicolumn{2}{|c|}{ Solo } & \multirow[t]{2}{*}{ Uso } & \multirow{2}{*}{$\operatorname{Arg}_{\mathrm{H}_{2} \mathrm{O}}$} & \multirow[t]{2}{*}{ Argila } & \multirow[t]{2}{*}{ Silte } & \multirow[t]{2}{*}{ Areia } & \multirow[t]{2}{*}{$\mathbf{A M F}$} & \multirow[t]{2}{*}{ Dp } & \multirow[t]{2}{*}{ GF } & \multirow[t]{2}{*}{ Água a -6 kPa } \\
\hline U.M.(1) & Classe $^{(2)}$ & & & & & & & & & \\
\hline & & & & & $\mathrm{g} \mathrm{kg}^{-1}-$ & & - & $\mathrm{Mg} \mathrm{m}^{-3}$ & $\%$ & $\mathrm{~m}^{3} \mathrm{~m}^{-3}$ \\
\hline \multirow{3}{*}{ Erechim } & \multirow{3}{*}{ LVaf } & natural & $240,6 b$ & $760,7 \mathrm{a}$ & $209,6 \mathrm{c}$ & $29,7 \mathrm{e}$ & 7,6 & 2,62 & 68 & 0,42 \\
\hline & & cultivado & $424,4 \mathrm{a}$ & $683,1 b$ & $277,6 \mathrm{~b}$ & $39,3 \mathrm{~d}$ & 6,2 & 2,59 & 38 & 0,42 \\
\hline & & Média & 332,5 & 721,9 & 243,6 & 34,5 & 6,9 & 2,61 & 54 & 0,42 \\
\hline \multirow{3}{*}{$\begin{array}{l}\text { Santo } \\
\text { Ângelo }\end{array}$} & \multirow{3}{*}{$\mathrm{LVdf}$} & natural & $238,7 \mathrm{~b}$ & $680,2 b$ & $255,3 \mathrm{~b}$ & $64,5 b$ & 12,6 & 2,62 & 65 & 0,44 \\
\hline & & cultivado & $286,4 \mathrm{~b}$ & $578,5 \mathrm{c}$ & $371,4 \mathrm{a}$ & $50,1 \mathrm{c}$ & 12,3 & 2,70 & 51 & 0,41 \\
\hline & & Média & 259,8 & 629,4 & 313,3 & 57,3 & 12,5 & 2,66 & 59 & 0,43 \\
\hline \multirow{3}{*}{ Cruz Alta } & \multirow{3}{*}{$\mathrm{LVd}$} & natural & $84,7 \mathrm{~d}$ & $227,6 \mathrm{~d}$ & $109,9 d$ & $662,5 \mathrm{a}$ & 104,4 & 2,68 & 62 & 0,37 \\
\hline & & cultivado & $124,5 \mathrm{c}$ & $209,7 d$ & $151,7 d$ & $638,6 \mathrm{a}$ & 101,8 & 2,77 & 41 & 0,35 \\
\hline & & Média & 104,6 & 215,1 & 134,3 & 650,6 & 103,1 & 2,73 & 51 & 0,36 \\
\hline
\end{tabular}

(1) Unidade de Mapeamento - Brasil (1973); (2) Embrapa (2006); LVaf = Latossolo Vermelho aluminoférrico; LVdf = Latossolo Vermelho distroférrico; $\mathrm{LVd}=$ Latossolo Vermelho distrófico; $\mathrm{Arg}_{\mathrm{H} 2 \mathrm{O}}=$ argila dispersa em água; $\mathrm{AMF}=$ areia muito fina. Médias seguidas pela mesma letra na mesma coluna não diferem pelo teste de Tukey a $5 \%$. 
Quadro 3. Características químicas dos solos

\begin{tabular}{|c|c|c|c|c|c|c|c|c|}
\hline $\begin{array}{c}\text { Solo } \\
\text { Unidade de Mapeamento }^{1}\end{array}$ & & & pH ${ }_{\text {H20 }}$ & pH $\mathbf{K C l}$ & $\Delta \mathbf{p H}$ & $\mathrm{CO}$ & $\mathrm{Fe}_{\mathrm{o}}$ & $\mathrm{Fe}_{\mathrm{d}}$ \\
\hline & Classe $^{2}$ & Uso & & & & $\longrightarrow$ & - $\mathrm{g} \mathrm{kg}$ & 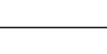 \\
\hline \multirow{3}{*}{ Erechim } & \multirow{3}{*}{ LVaf } & natural & 4,08 & 3,68 & $-0,40$ & 2,99 & 2,40 & 95,18 \\
\hline & & cultivado & 5,65 & 4,55 & $-1,10$ & 2,31 & 2,53 & 94,74 \\
\hline & & Média & 4,87 & 4,12 & $-0,75$ & 2,65 & $2,47 \mathrm{a}$ & $94,96 \mathrm{a}$ \\
\hline \multirow{3}{*}{ Santo Ângelo } & \multirow{3}{*}{$\mathrm{LVdf}$} & natural & 4,99 & 4,46 & $-0,53$ & 2,20 & 2,67 & 92,31 \\
\hline & & cultivado & 5,60 & 4,50 & $-1,10$ & 1,95 & 1,92 & 92,51 \\
\hline & & Média & 5,30 & 4,48 & $-0,82$ & 2,08 & $2,30 \mathrm{a}$ & $92,41 \mathrm{a}$ \\
\hline \multirow{3}{*}{ Cruz Alta } & \multirow{3}{*}{$\mathrm{LVd}$} & natural & 5,06 & 3,92 & $-1,14$ & 1,49 & 1,57 & 17,25 \\
\hline & & cultivado & 5,54 & 4,61 & $-0,93$ & 1,62 & 1,16 & 19,31 \\
\hline & & Média & 5,30 & 4,27 & $-1,04$ & 1,55 & $1,37 \mathrm{~b}$ & $18,28 \mathrm{~b}$ \\
\hline
\end{tabular}

${ }^{1}$ Brasil (1973); ${ }^{2}$ Embrapa (2006); LVaf = Latossolo Vermelho aluminoférrico; LVdf = Latossolo Vermelho distroférrico; LVd = Latossolo Vermelho distrófico; $\mathrm{CO}$ = carbono orgânico; $\mathrm{Fe}_{\mathrm{o}}$ = ferro extraído com oxalato de amônio ácido e $\mathrm{Fe}_{\mathrm{d}}=$ ferro extraído com ditionito-citrato-bicarbonato(DCB). Médias seguidas pela mesma letra na mesma coluna não diferem significativamente pelo teste de Tukey a $5 \%$.

Para a condição de solo pré-umedecido, o solo da parcela foi saturado por pressão de 10 cca, durante a noite, por $12 \mathrm{~h}$. Após, o solo foi mantido a uma tensão de 60 cca $(6 \mathrm{kPa})$, por um período de $2 \mathrm{~h}$, para posterior aplicação da chuva simulada, mantendo-se a tensão de $6 \mathrm{kPa}$.

As chuvas foram aplicadas por meio de um simulador de chuvas (Veejet 80-150/Spraying Systems Company, USA). Em todos os testes, foram aplicadas chuvas simuladas com três repetições cada, com intensidade média de $88 \mathrm{~mm} \mathrm{~h}^{-1}\left(2,44 \times 10^{-5} \mathrm{~m} \mathrm{~s}^{-1}\right)$, durante $180 \mathrm{~min}$.

O escoamento superficial foi amostrado em potes plásticos colocados na extremidade inferior da calha coletora. As amostras foram coletadas durante $60 \mathrm{~s}$, com intervalos de 2 min entre as coletas, foram pesadas e, após, fora adicionados $5 \mathrm{~mL}$ de solução concentrada de sulfato duplo de $\mathrm{Al}$ e $\mathrm{K}$ $\left(\mathrm{KAl}\left(\mathrm{SO}_{4}\right)_{2} \cdot 12 \mathrm{H}_{2} \mathrm{O}\right.$ a $\left.5 \%\right)$, para a decantação das partículas. Após 24 h, o sobrenadante foi succionado e os potes foram levados para estufa a $50^{\circ} \mathrm{C}$, até atingir peso constante, sendo, posteriormente, pesados com ou sem o solo.

A taxa de desagregação do solo em entressulcos foi considerada como igual à taxa de aporte de sedimentos. Após a plotagem dos valores de taxa de desagregação $\left(\mathrm{D}_{\mathrm{i}}\right)$ para cada intervalo de coleta, foi ajustada uma equação para determinar o ponto de máxima. Quando não houve ponto de máxima, foi utilizada a média dos últimos cinco valores de $\mathrm{D}_{\mathrm{i}}$.

$\mathrm{O}$ fator $\mathrm{K}_{\mathrm{i}}$ foi determinado conforme proposto pelo modelo WEPP (Flanagan \& Nearing, 1995), em condições de solo descoberto, recém-preparado e sem resíduos, por meio da equação (1).
O fator declividade em entressulcos $\left(\mathrm{S}_{\mathrm{f}}\right)$ foi determinado, conforme Liebenow et al. (1990), pela seguinte expressão:

$$
\mathrm{S}_{\mathrm{f}}=1,05-0,85 \mathrm{e}^{-4 \operatorname{sen} \theta}
$$

em que $\theta$ é o ângulo do declive (graus).

$\mathrm{O}$ fator $\mathrm{K}_{\mathrm{i}}$, para uma declividade padrão de $45^{\circ}$, também foi estimado por meio de equações propostas pelo modelo WEPP (Alberts et al., 1995):

a) Para solos com $30 \%$ ou mais de areia:

$$
\mathrm{K}_{\mathrm{ib}}=2728000+19210000 \mathrm{amf}
$$

b) Para solos com menos de $30 \%$ de areia:

$$
\mathrm{K}_{\mathrm{ib}}=6054000-5513000 \mathrm{arg}
$$

em que $\mathrm{K}_{\mathrm{ib}}$ é o fator de erodibilidade básica do solo em entressulcos ( $\left.\mathrm{kg} \mathrm{s} \mathrm{m}^{-4}\right)$; amf é a fração de areia muito fina do solo $\left(\mathrm{kg} \mathrm{kg}^{-1}\right)$ e arg é a fração de argila do solo $\left(\mathrm{kg} \mathrm{kg}^{-1}\right)$.

A análise estatística dos dados foi realizada por meio do programa SAS (2003). Foi utilizado o delineamento fatorial, com dois fatores e três níveis, análises de variância (ANOVA) e comparações múltiplas de médias, com ajuste pelo teste de Tukey, a $5 \%$. Foram utilizadas correlações simples e análises de regressão linear múltipla, com base no teste " $t$ ".

\section{RESULTADOS E DISCUSSÃO}

Os valores de taxa de desagregação e de erodibilidade em entressulcos do solo LVd foram, 
aproximadamente, o dobro dos observados para os solos LVaf e LVdf (Quadro 4). Isso pode ser devido ao alto teor de areia do solo LVd, principalmente de areia muito fina (Quadro 1), baixo índice de estabilidade de agregados em água (Quadro 2) e baixo teor de $\mathrm{C}$ orgânico (Quadro 3).

Quadro 4. Fator de erodibilidade do solo em entressulcos $\left(K_{i}\right)$

\begin{tabular}{lccc}
\hline \multirow{2}{*}{ Uso } & Erechim $^{(1)}$ & Santo Ângelo $^{(1)}$ & Cruz Alta $^{(1)}$ \\
\cline { 2 - 4 } & $\mathbf{L V a f}^{(2)}$ & LVdf $^{(2)}$ & LVd $^{(2)}$ \\
\cline { 2 - 4 } & \multicolumn{3}{c}{$\mathrm{kg} \mathrm{s} \mathrm{m}^{-4} \times 10^{6}$} \\
Natural & $0,75 \mathrm{Ab}$ & $0,77 \mathrm{Ab}$ & $1,41 \mathrm{Aa}$ \\
Cultivado & $0,77 \mathrm{Ab}$ & $1,16 \mathrm{Aab}$ & $1,54 \mathrm{Aa}$ \\
Média & 0,76 & 0,97 & 1,48 \\
\hline
\end{tabular}

${ }^{(1)}$ Brasil (1973); ${ }^{(2)}$ Embrapa (2006); LVaf = Latossolo Vermelho aluminoférrico; LVdf = Latossolo Vermelho distroférrico; LVd = Latossolo Vermelho distrófico; Letras maiúsculas comparam médias de linhas na mesma coluna. Letras minúsculas comparam médias de colunas na mesma linha. Médias seguidas pela mesma letra não diferem pelo teste de Tukey a $5 \%$.

Em geral, solos francos, franco siltosos e siltosos são muito susceptíveis à erosão hídrica em entressulcos, em relação aos solos argilosos (Meyer \& Harmon, 1984). Possivelmente, os agregados dos solos LVaf e LVdf foram resistentes à quebra pelo impacto da gota da chuva e à ação do escoamento superficial, impactado pela chuva. Resultados semelhantes foram encontrados por Le Bissonais \& Singer (1993), os quais estudaram alguns solos da Califórnia e verificaram que os solos com maior teor de $\mathrm{C}$ orgânico e de óxidos de $\mathrm{Fe}$ e $\mathrm{Al}$ (extraídos com ditionito-citrato-bicarbonato) apresentaram maior taxa de infiltração e menor erosão em entressulcos.

O fator de erodibilidade do solo em entressulcos foi obtido pela média entre o fator $\mathrm{K}_{\mathrm{i}}$ do solo natural e o do solo cultivado, pois não há diferença significativa em relação ao fator $K_{i}$ entre esses tipos de uso do solo (Quadro 4). O fator $K_{\mathrm{i}}$ determinado experimentalmente nos solos LVaf, LVdf e LVd foi, respectivamente, de $0,76 \times 10^{6} ; 0,97 \times 10^{6}$ e $1,48 \times 10^{6} \mathrm{~kg} \mathrm{~s} \mathrm{~m}^{-4}$. Esses valores situam-se dentro da faixa de variação do fator $\mathrm{K}_{\mathrm{i}}$ do modelo WEPP (Flanagan \& Nearing, 1995),

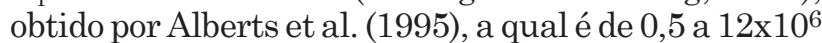
$\mathrm{kg} \mathrm{s} \mathrm{m}^{-4}$. No Rio Grande do Sul, Braida \& Cassol (1996) obtiveram em campo um fator $\mathrm{K}_{\mathrm{i}}$ de 5,1 x $10^{6} \mathrm{~kg} \mathrm{~s} \mathrm{~m}^{-4}$ em um Argissolo Vermelho distrófico arênico. Albuquerque et al. (2000) obtiveram, em laboratório e para sete solos, valores de $K_{i}$ que variaram de 0,17 a $1,96 \times 10^{6} \mathrm{~kg} \mathrm{~s} \mathrm{~m}^{-4}$. Cassol \& Lima (2003), em campo, encontraram um fator $\mathrm{K}_{\mathrm{i}}$ de $2,83 \times 10^{6} \mathrm{~kg} \mathrm{~s} \mathrm{~m}^{-4}$ para um Argissolo Vermelho distrófico típico franco-argiloarenoso. Cantalice (2001) obteve, em campo e laboratório, o fator $\mathrm{K}_{\mathrm{i}}$ médio de $2,55 \times 10^{6} \mathrm{~kg} \mathrm{~s} \mathrm{~m}{ }^{-4}$, para um Argissolo Vermelho distrófico típico.

A estimativa do fator $K_{i}$ pelas equações do WEPP (Equações 3 e 4) superestimou em 2,4 a 3,6 vezes os valores obtidos experimentalmente (Figura 1), possivelmente por terem sido as equações utilizadas no WEPP desenvolvidas com base em solos formados com taxas de intemperismo menores que as dos Latossolos brasileiros.

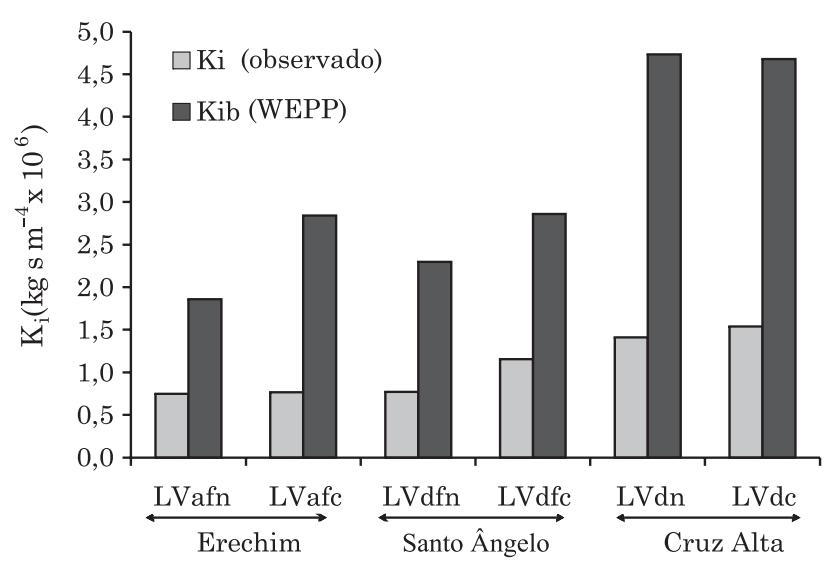

Figura 1. Fator de erodibilidade do solo em entressulcos observado $\left(K_{i}\right)$ e estimado pelo uso da textura (Alberts et al., 1995) $\left(\mathrm{K}_{\mathrm{ib}}\right)$ utilizado no modelo WEPP; LVaf = Latossolo Vermelho aluminoférrico; LVdf = Latossolo Vermelho distroférrico; LVd = Latossolo Vermelho distrófico; $\mathbf{n}=$ natural $; \mathbf{c}=$ cultivado.

Albuquerque (1998) também avaliou o uso das equações (3) e (4) do modelo WEPP, para a estimativa do fator $K_{i}$ para solos do Rio Grande do Sul, e verificou que o modelo superestimou em seis vezes os valores obtidos em laboratório.

O modelo WEPP utilizou as frações granulométricas areia muito fina e argila para estimar a erodibilidade em entressulcos, conforme as equações (3) e (4). Com base nos resultados obtidos no presente estudo, bem como nos de Albuquerque (1998), constatou-se que apenas a utilização das frações granulométricas pode não ser suficiente para explicar a variação na erodibilidade do solo em entressulcos, apesar de a granulometria influenciar a resistência do solo à desagregação em entressulcos (Meyer \& Harmon, 1984).

$\mathrm{O}$ fator $\mathrm{K}_{\mathrm{i}}$ apresentou correlação altamente significativa $\left(\mathrm{r}^{2}=0,81^{* *}\right)$ com o índice de estabilidade de agregados em água de Kemper \& Rosenau (1986). A estabilidade dos agregados influencia a desagregação do solo pelo impacto das gotas da chuva, pois combina e integra os efeitos de praticamente todas as propriedades texturais e químicas, bem como suas interações dentro de um único valor (Legout et al., 
2005). Meyer \& Harmon (1984) e Albuquerque et al. (2000) também verificaram correlação altamente significativa entre o índice de estabilidade de agregados em água e a erodibilidade do solo em entressulcos.

Após uma análise de regressão entre as propriedades dos solos avaliados no presente estudo, foi obtido um modelo (Stepwise) com um coeficiente de determinação da erodibilidade em entressulcos de $0,974^{* *}(p<0,01)$. Esse modelo pode ser expresso da seguinte forma:

$$
\mathrm{K}_{\mathrm{i}}=\left[1,982-8,886 \cdot 10^{-4}(\mathrm{Arg})-0,228\left(\mathrm{Fe}_{\mathrm{o}}\right)\right] \times 10^{6}
$$

sendo $\mathrm{K}_{\mathrm{i}}$ o fator de erodibilidade do solo em entressul$\cos \left(\mathrm{kg} \mathrm{s} \mathrm{m}^{-4}\right)$; Arg o teor de argila total $\left(\mathrm{g} \mathrm{kg}^{-1}\right)$ e Fe $_{o}$ o teor de óxido de $\mathrm{Fe}$ extraído com oxalato de amônio ácido $\left(\mathrm{g} \mathrm{kg}^{-1}\right)$.

A equação (5) utiliza como uma das propriedades o teor de argila, de maneira semelhante à equação proposta pelo modelo WEPP, para estimar o fator $\mathrm{K}_{\mathrm{i}}$ de solos com menos de 30 \% de areia (equação 4). Essa semelhança deve-se, possivelmente, ao relativamente baixo teor de areia dos solos estudados. A presença de $\mathrm{Fe}_{0}$ na equação (5) proposta neste estudo, além do teor de argila, e ausente no modelo WEPP pode ser porque os Latossolos sofreram alto grau de intemperismo (Azevedo \& Bonumá, 2004), diferentemente dos solos para os quais o WEPP foi desenvolvido. Veiga et al. (1993) também obtiveram correlação significativa entre os óxidos de $\mathrm{Fe}_{0}$ e o fator $\mathrm{K}_{\mathrm{i}}$. Segundo os últimos autores, os óxidos promovem uma cimentação das partículas primárias do solo, originando agregados com alta estabilidade, os quais contribuem para a menor erodibilidade em entressulcos. Römkens et al. (1977) estudaram a erodibilidade global de sete subsolos dos EUA e obtiveram dados muito semelhantes aos obtidos para os Latossolos em estudo. Os autores concluíram que os óxidos de $\mathrm{Fe}$ e $\mathrm{Al}$, extraídos com DCB, de solos argilosos, combinados com propriedade granulométrica, estimaram adequadamente a erodibilidade global dos solos.

O modelo obtido e expresso na equação (5) é constituído por apenas duas propriedades, de determinação fácil e rápida em laboratório, quais sejam, o teor de argila e o de $\mathrm{Fe}_{\mathrm{o}}$. Assim, pode ser usado como uma ferramenta para estimar o fator $\mathrm{K}_{\mathrm{i}}$ (erodibilidade do solo em entressulcos) de Latossolols com características semelhantes aos estudados.

\section{CONCLUSÕES}

1. O fator de erodibilidade do solo em entressulcos $\left(\mathrm{K}_{\mathrm{i}}\right)$ dos solos LVaf, LVdf e LVd foi de, respectivamente, $0,76 \times 10^{6} ; 0,97 \times 10^{6}$ e $1,48 \times 10^{6} \mathrm{~kg} \mathrm{~s} \mathrm{~m}^{-4}$. Dentre os três Latossolos estudados, os mais argilosos apresentaram os menores valores do fator de erodibilidade em entressulcos.
2. $\mathrm{O}$ uso dos teores de areia muito fina (AMF) e de argila, conforme sugerido pelo modelo WEPP, não foi adequado para predizer a erodibilidade em entressulcos dos Latossolos do Rio Grande do Sul estudados, uma vez que superestimou os dados obtidos experimentalmente;

3. O teor de argila total e o de óxidos de Fe de baixa cristalinidade, extraído com oxalato de amônio ácido $\left(\mathrm{Fe}_{\mathrm{o}}\right)$, explicaram $97 \%(\mathrm{p}<0,01)$ da erodibilidade em entressulcos dos solos estudados, podendo, dessa forma, ser utilizados para a estimativa do fator de erodibilidade em entressulcos, para Latossolos com características semelhantes às dos solos estudados.

\section{LITERATURA CITADA}

ALBERTS, E.E.; NEARING, M.A.; WELTZ, M.A.; RISSE, L.M.; PIERSON, F.B.; ZHANG, J.M. LAFLEN, J.M. \& SIMANTON, J.R. Soil component. In: FLANAGAN, D.C. \& NEARING, M.A., eds. Water Erosion Prediction Project - WEPP. West Lafayette, USDA, 1995. p.1-47. (Report, 10)

ALBUQUERQUE, J.A. Suscetibilidade de alguns solos do Rio Grande do Sul à erosão em entressulcos. Porto Alegre, Universidade Federal do Rio Grande do Sul, 1998. 154p. (Tese de Doutorado)

ALBUQUERQUE, J.A.; CASSOL, E.A. \& REINERT, D.J. Relação entre a erodibilidade em entressulcos e estabilidade dos agregados. R. Bras. Ci. Solo, 24:141-151, 2000.

AZEVEDO, A.C. \& BONUMÁ, A.S. Partículas coloidais, dispersão e agregação em Latossolos. Ci. Rural, 34:609$617,2004$.

BLAKE, G.R. \& HARTGE, K.H. Physical and mineralogical methods. In: KLUTE, A., ed. Methods of soil analysis. 2.ed. Madison, American Society of Agronomy, Soil Science Society of America, 1986. p.363-382.

BRAIDA, J.A. \& CASSOL, E.A. Erodibilidade em sulcos e em entressulcos de um Podzólico Vermelho-Escuro francoarenoso. R. Bras. Ci. Solo, 20:127-134, 1996.

BRASIL. Departamento Nacional de Pesquisa Agropecuária. Divisão de Pesquisa Pedológica. Levantamento de reconhecimento dos solos do Estado do Rio Grande do Sul. Recife, 1973. 431p. (Boletim Técnico, 30)

CANTALICE, J.R.B. Escoamento e erosão em sulcos e em entressulcos em distintas condições de superfície do solo. Porto Alegre, Universidade Federal do Rio Grande do Sul, 2001. 140p. (Tese de Doutorado)

CASSOL, E.A. \& LIMA, V.S. Erosão em entressulcos sob diferentes tipos de preparo e manejo do solo. Pesq. Agropec. Bras., 38:117-124, 2003.

ELLIOT, W.J.; LIEBENOW, A.M.; LAFLEN, J.M. \& KHOL, K.D. A compendium of soil erodibility data from WEPP cropland soil field erodibility experiments 1987, 1988. West Lafayette, USDA-ARS, 1989. (Report, 3) 
EMPRESA BRASILEIRA DE PESQUISA AGROPECUÁRIA EMBRAPA. Centro Nacional de Pesquisa de Solos. Sistema brasileiro de classificação de solos. 2.ed. Brasília, 2006.306p.

EMPRESA BRASILEIRA DE PESQUISA AGROPECUÁRIA EMBRAPA. Centro Nacional de Pesquisa de Solos. Manual de métodos de análise de solos. 2.ed. Rio de Janeiro, 1997. 212p. (Embrapa-CNPS. Documento, 1)

FLANAGAN, D.C.; ASCOUGH II, J.C.; NICKS, A.D.; NEARING M.A. \& LAFLEN, J.M. Overview of the WEPP erosion prediction model. In: FLANAGAN, D.C. \& NEARING, M.A., eds. Water erosion prediction project WEPP, Technical Documentation. West Lafayette, USDAARS-NSERL, 1995 (NSERL Report, 10)

FLANAGAN, D.C. \& NEARING, M.A. Water erosion prediction project: Technical Documentation. West Lafayette, USDA-ARS-NSERL, 1995 (NSERL Report, 10)

KÄMPF, N. \& CURI, N. Argilominerais em solos brasileiros. In: CURI, N.; MARQUES, J.J.; GUILHERME, L.R.G.; LIMA, J.M.; LOPES, A.S. \& ALVAREZ V., V.H. Tópicos em ciência do solo. Viçosa, MG, Sociedade Brasileira de Ciência do Solo, 2003. v.3. 2003. p.1-54.

KEMPER, W.D. \& ROSENAU, R.C. Aggregate stability and size distribution. In: KLUTE, A., ed. Methods of soil analysis. 2.ed. Madison, American Society of Agronomy, Soil Science Society of America, 1986. p.425-441.

LE BISSONAIS, Y. \& SINGER M.J. Seal formation, runoff, and interrill erosion from seventeen California soils. Soil Sci. Soc. Am. J., 57:224-229, 1993.

LEGOUT, C.; LEGUÈDOIS S. \& LE BISSONAIS, Y. Aggregate breakdown dynamics under rainfall compared with aggregate stability measurements. Eur. J. Soil Sci., 56:225-237, 2005.
LIEBENOW, A.M.; ELLIOT, W.J.; LAFLEN, J.M. \& KOHL, K.D. Interrill erodibility: Collection and analysis of data from cropland soils. Trans. Am. Soc. Agron. Eng., 33:18821888,1990 .

MEHRA, O.P. \& JACKSON, M.L. Iron oxide removal from soils and clays by a dithionite-citrate system buffered with sodium bicarbonate. In: NATIONAL CONFERENCE CLAYS \& CLAY MINERALS, 7., Ottawa, 1960. Proceedings. Ottawa, 1960. p.317-327.

MEKARU, T. \& UEHARA, G. Anion adsorption in ferruginous tropical soils. Soil Sci. Soc. Am. Proc., 36:296-300, 1972.

MEYER, L.D. Rain intensity affects interrill erosion. Trans. Am. Soc. Agron. Eng., 24:1472-1475, 1981.

MEYER, L.D. \& HARMON, W.C. Susceptibility of agricultural soils to interrill erosion. Soil Sci. Soc. Am. J., 48:11521157, 1984.

RÖMKENS, M.J.M.; ROTH, C.B. \& NELSON, D.W. Erodibility of select clay subsoils in relation to physical and chemical properties. Soil Sci. Soc. Am. J., 41:954960, 1977.

SAS Institute. Statistical Analytical Systems - SAS for Windows Procedures Guide: Version 9.1, Cary, 2002-2003.

SCHWERTMANN, U. Differenzierung der eisen oxide des bodens durch extraktion unit saurer ammoniumoxalatlosung. Z. Pflanzenernaehr. Bodenkd., 105: 139-202, 1964.

SHIMADZU - Total Organic Carbon Analyzer (TOC-V CSH). Manual do Usuário, Japão, 2001. 144p.

VEIGA, M.; CABEDA, M.S.V. \& REICHERT, J.M. Erodibilidade em entressulcos de solos do Rio Grande do Sul. R. Bras. Ci. Solo, 17:289-298, 1993. 
